DOI: $10.17805 / \mathrm{ggz} .2020 .2 .2$

\title{
Права будущих поколений и регулирование геномных исследований ${ }^{*}$
}

С. Ю. Шевченко

Институт философии РАН;

Российский национальный исследовательский медииинский университет имени Н. И. Пирогова, г. Москва

Развитие геномных технологий может оказать влияние на то, какой будет жизнь будущих поколений. При этом речь идет не только о формировании технологических условий их жизни, но и о том, с каким геномом люди могут появиться на свет в будущем, а также о том, кто будет владеть и распоряжаться данными об их геноме. Последний аспект и является предметом исследования в настоящей статье. Создаваемые сегодня формы регулирования и саморегулирования геномных исследований способны оказать серьезное влияние на защиту частной жизни еще не рожденных людей, соответственно, их интересы должны быть представлены в рамках обсуждения этих форм.

В статье показано, что такое представительство обладает значимыми особенностями. Представляемые обретают агентность исключительно в рамках репрезентации своих прав и интересов, и потому не способнь авторизовывать своих представителей или оспаривать принимаемые от их имени решения. При этом очевиден риск произвольной интерпретации прав и интересов представляемых. Однако полной релятивизации противостоит сама суть интерпретачии, раскрываемая через соавторство уже существовавшего до нас текста, корпуса права (Рональд Дворкин) или через действия актора в уже созданном заранее образе (Филип Петтит). Интерпретируя интересы будущих поколений, их представители могут опираться как на существующие правовые представления, так и на дополнительные формы контроля за распоряжением персональными (геномными) данными, которые могут понадобиться агентам, еще не достигшим правосубъектности. В заключении статьи намечены некоторые опорные точки такого регулирования.

\footnotetext{
* Исследование выполнено при финансовой поддержке РФФИ в рамках научного проекта № 18-29-14100.

The research was conducted with financial support from the Russian Foundation for Basic Research within the framework of the project No. 18-29-14100.
} 
Ключевые слова: геномные исследования; будущие поколения; политическое представительство; делегирование агентности; информированное согласие

\title{
The Rights of Future Generations and the Regulation of Genomic Research
}

\author{
S. Yu. Shevchenko
}

Institute of Philosophy, Russian Academy of Sciences; Pirogov Russian National Research Medical University, Moscow

Emerging genomic technologies may have a significant impact on how future generations will live. This is not only about the development of technological conditions of their life, but also about what kind of genome people will have a chance to be born with in the future, as well as about who will own and manage their genomic data. The latter aspect is the subject of the research in this article. The forms of regulation and self-regulation of genomic research, which are being created today, will have a serious impact on protecting the privacy of unborn (or even unconceived) people, that is why their interests should be represented in the discussion of these forms.

Such representation has significant features which are discussed in the article. In our case, unborn or unconceived people acquire agency only due to representation of their rights and interests, and therefore are not able to authorize their representatives or dispute decisions made on their behalf. At the same time, the risk of arbitrary interpretation of the rights and interests of the represented ones is $o b-$ vious. However, the arbitrariness is opposed by the very essence of interpretation that is revealed through the co-authorship of the pre-existing text, corpus of law (Ronald Dworkin) or through the actor's actions in the already created image (Philip Pettit). Interpreting the interests of future generations, their representatives can rely both on existing legal ideas and on additional forms of control over the management of personal (genomic) data that may be needed by agents who have not yet reached legal capacity. In conclusion, the article outlines some reference points for such regulation.

Keywords: genomic research; future generations; political representation; delegation of agency; informed consent

\section{ВВЕДЕНИЕ}

Эксперименты по редактированию человеческого генома за последние пять лет стали одним из главных предметов дискуссии о формах биоэтической и правовой регламентации новых технологий. Особенно жаркие дебаты были вызваны сообщением китайского ученого Хэ Цзянькуя о рождении в 2018 г. 
близнецов с искусственно измененным геном CCR5, что должно было обусловить их нечувствительность к ВИЧ (Jasanoff, Hurlbut, 2018). При этом широкая вовлеченность мирового академического сообщества в дискуссии о допустимости подобных экспериментов вызвана не только их радикализмом, попыткой конструирования «человеческой природы» на наиболее фундаментальном биологическом уровне - эта регулятивная проблема высвечивает важные аспекты взаимоотношений между прошлыми, настоящими и будущими поколениями. Изменения, внесенные в геном индивида, значимы для всех его / ее потомков. Но и сама содержащаяся в геноме информация позволяет судить о семейной истории человека - наследственных заболеваниях и происхождении его / ее предков, также эти данные позволяют вскрыть факты рождения коголибо из предков человека от близкородственных связей (Ижевская, 2015). Такие сведения могут стать основанием для стигматизации индивида. Обычно проблемы сбора, хранения и обработки генетических данных рассматриваются через призму отношений института, осуществляющего эти процедуры с данными или биобразцами, и индивида, дающего согласие на эти процедуры. Однако речь может идти о данных, сбор и обработка которых может оказаться значимыми для еще недееспособного человека (ребенка), а возможно, и для еще не рожденного или не зачатого ребенка. В обычном, «классическом», случае дееспособный агент дает согласие на операции со своими генетическими данными и может в любой момент своей жизни его отозвать. Но возможны и этико-правовые коллизии, не подходящие под данный тип отношений - приведем три примера:

1. Сбор генетических данных или биоматериалов несовершеннолетнего осуществляется с согласия его / ее родителей (законных представителей).

2. Сбор данных осуществляется в рамках преимплантационной диагностики - индивид, чей геном исследуется, уже зачат, но еще не рожден на момент получения данных.

3. До зачатия (естественного или с применением процедуры ЭКО) исследуется геном родителей, генетические вариации их половых клеток. Речь в таком случае не идет о данных полного генома конкретного индивида, но сведения, позволяющие предполагать его / ее наследственные медицинские риски, а также его / ее семейная история могут хранится или распространятся без согласия и ведома индивида. В обобщенном виде эти коллизии могут быть обозначены как имеющие отношение к правам и интересам еще не рожденных и не зачатых людей. Данные о редких генетических особенностях даже далеких предков индивида могут оказаться значимыми для него / нее. Они могут угрожать его / ее частной жизни, влиять на понимание собственных жизненных шансов, но вместе с тем и давать шанс на профилактику наследственных патологий. 
Еще на заре развития современных геномных технологий довольно остро обсуждалась проблемы «наших генетических обязательств перед будущими поколениями» или «влияния наших политических решений на идентичность будущих поколений». Само употребление первой формулировки зачастую маркировало тяготение автора к евгеническому взгляду на интересы или права будущих поколений. Опасные, нежелательные, генетические варианты все чаще встречаются в человеческой популяции, наша обязанность - обеспечить потомков здоровым генофондом (Jones, 1976). Такая постановка вопроса исходит из понимания, что интересы и права будущих поколений заключаются в их биомедицинском благополучии (как оно понимается сегодня). Подобная же риторика используется и сегодня для обоснования того, что участие в геномных исследованиях является бесспорной моральной обязанностью в отношении будущих поколений и, в особенности, непосредственных потомков индивида, принимающего решения о таком участии. Не соглашаясь на сбор собственной генетической информации он / она лишают своих потомков возможности пользоваться плодами развития биомедицины. Значимые для детей и внуков генетические вариации исключаются из крупных популяционных исследований, потенциал их влияния на здоровье остается неизвестным, поэтому в будущем врачи не смогут предотвратить соответствующие этим вариациям риски (Knoppers, Kleiderman, 2019).

Однако проблему прав будущих поколений можно поставить, и не ограничивая их интересы биомедицинским благополучием, понятым в перспективе текущего уровня развития технологий. Больше трех десятилетий обсуждается поставленная Дереком Парфитом проблема не-идентичности, в рамках которой также может быть осмыслено представительство будущих поколений. Коротко она может быть обозначена следующим образом: то, кто появится на свет в будущем и каким геномом будут обладать эти люди, зависит от наших сегодняшних решений, от того, как репрезентированы сегодня права и интересы будущих поколений (Parfit, 1982). Мы предлагаем расширить ее толкование - «идентичность» еще нерожденных людей зависит не только от их наследственного аппарата, но и от того в каком информационном, правовом окружении они появятся на свет. Наследственные черты будущих поколений обретают конкретное значение именно в этом окружении. Сегодняшнее регулирование геномных исследований может оказаться значимым фактором стигматизации отдельных индивидов или групп в будущем. В этой перспективе необходимо предусмотреть формы контроля над распространением биомедицинских данных для тех, кто не давал информированного согласия на их получение и передачу, но на чьих правах такое распространение непосредственно сказывается. Такие формы контроля будут предложены в заключительной части текста. 
В основных частях данной статьи мы рассмотрим формы регулирования и саморегулирования геномных исследований в аспекте их значимости для прав будущих поколений. В первую очередь речь пойдет о сборе, хранении и обработке генетических данных как о рутинной составляющей геномных исследований. В рамках этого рассмотрения мы попытаемся ответить на два основных вопроса:

1. Каким образом можно обеспечить правовое представительство будущих поколений в сегодняшних дискуссиях о регулировании геномных исследований?

2. Как права будущих поколений могут быть учтены в рамках регулирования и саморегулирования геномных исследований?

В следующем фрагменте статьи первый из этих вопросов толкуется в оптике акторно-сетевого подхода. Хотя его применение для решения поставленных вопросов может показаться несколько странным, оно обусловлено тем, что поставленная проблема необычна и для философии права, и для политической философии. Обе эти дисциплины обычно имеют дело с представительством живых или хотя бы некогда живших людей. Перед нами необычный источник делегирования - будущие поколения. Прояснить особенности представления их прав и интересов можно в рамках подхода, согласно которому любые вещи или сущности способны делегировать друг другу возможность действовать от их имени.

\section{«ГОВОРИТЬ ОТ ИМЕНИ» ЛЮДЕЙ И АРТЕФАКТОВ - ДЕЛЕГИРОВАНИЕ АГЕНТНОСТИ У БРУНО ЛАТУРА}

Итак, можно попытаться поставить проблему такого представительства в терминах делегирования агентности, как оно понимается в акторно-сетевой теории - особого направления в социальных исследованиях науки и технологии. Ее основоположник Бруно Латур легко переходит от «говорения от имени» некоторого собрания людей, например, профсоюзного коллектива, к говорению от имени не-человеческих агентов - технических устройств, бактерий, сил природы (Латур, 2013). Все участники процесса делегирования выступают как актанты - индивиды или объекты совершающие действия или подвергающиеся воздействию.

Вполне логичным кажется следующее замечание: для того чтобы быть актантом, необходимо существовать - в том смысле, что объект или индивид способны «дать сдачи», оказать сопротивление произвольному приписыванию свойств или склонностей совершать некоторые действия. Может быть установлен некоторый предел, ограничивающий произвол «говорящего от имени» профсоюза или бактерии. Нельзя с легкостью утверждать, что бактерия погибает под действием антибиотика А, что она не способна выжить на кожных 
покровах человека - если бактерия склонна демонстрировать обратное. Бактерия актуально существует — в этом условие ее агентности, которую она делегирует.

Однако у Латура вещь получает возможность действовать, именно потому что ей была делегирована агентность ученых или инженеров (Напреенко, 2015: 112). Например, только благодаря открытием Пастера бактерии обрели тот значительный «вес» в гигиенических нормах и практиках, каким они обладают последние полтора века. Инженер же создает модели устройств так же, как писатель - своих героев. Сам Латур описывает сети делегирования агентности как столь запутанные, что невозможно установить, насколько адекватно действует делегат. Автор не обладает привилегированным правом на интерпретацию собственного текста, созданные им герои начинают жить самостоятельной жизнью. Самость исчерпывается набором действий, совершенных от ее имени (там же: 117). Т. е. актуально извлечь критерии, которые отличают адекватное представительство от произвола, невозможно даже при «говорении от имени» существующих собраний людей и вещей.

Однако остановимся исключительно на (практически горьковской) аналогии между писателем и инженером и попытаемся истолковать ее значение в рамках проблемы способа и адекватности делегирования агентности. Как справедливо отмечают критики Латура из лагеря спекулятивных реалистов, бактерии существовали и до Пастера. Однако инженер создает нечто новое, в этом его отличие от ученого, занятого «открытием». Создаваемое инженером «новое» представляет собой сборку из имеющихся вещей (и их свойств) и человеческих практик. Т. е., конструируя некоторое устройство, инженер ориентируется на определенные семиотические поля - те или иные фрагменты мира не могут обладать абсолютно произвольным значением. Самость может быть понята через совокупность совершаемых от ее имени действий, но и эта совокупность зависит от способа задания самости.

Перед нами в данном случае - нетривиальная семиотическая задача. Инженер создает своих «героев» в определенном семантическом поле. В нашем случае герои - группа технологий и биотехнологических практик - уже созданы. Это биобанкинг, технологии сбора, хранения и обработки генетических данных, а также редактирование человеческого генома. Необходимо создать, сконструировать семантическое поле, в котором эти практики могли бы быть прочитаны или истолкованы с позиции прав и интересов будущих поколений. Продолжая литературные аналогии, мы покажем, что понять литературных героев означает вступить с ними во взаимодействие, пространством же для него может быть театральная сцена. При взаимодействии с имеющимися технологическими актантами становится возможным конституировать самость играемого героя - будущих поколений. 
Как мы покажем в следующем разделе, данная театральная аналогия не случайна, она используется в рамках политической философии для прояснения одного из видов представительства — как нам кажется, наиболее близкого к описанным во введении задачам.

\section{ПРЕДСТАВИТЕЛЬСТВО КАК ИНТЕРПРЕТАЦИЯ}

На протяжении значительной части истории политической мысли представительство считалось явлением вторичным по отношению к непосредственному принятию решений собранием граждан. До сих пор широко обсуждается критика Жан-Жак Руссо в адрес представительства как ущербной формы воплощения «общей воли» народа. Последняя может быть воплощена только в рамках принятия решений собранием всех ее носителей. При этом содержание общей воли видится им как очевидное для всякого, поэтому решение принимается без дискуссий или дебатов (Руссо, 1998: 291-293). Но для выражения «общей воли» требуется одномоментное физическое присутствие всех ее носителей на некотором форуме. Для таких периодически повторяющихся всенародных собраний требуется, чтобы государство было достаточно малым (походило на древнегреческий полис) и чтобы у его граждан было достаточно свободного времени для участия в гражданских делах. На то, что эти требования не отвечают реалиям времени, обращали внимание Джеймс Мэдисон (один из отцов-основателей США) и Эммануэль-Жозеф Сийес (одна из ключевых политических фигур Франции периода Конвента и Директории), которых можно назвать поздними современниками Руссо. Представительство в их понимании обусловлено не только географическими и экономическими факторами, но и тем, что позволяет избежать тенденциозного и необдуманного поведения, свойственного представляемым «массам». При этом народные представители перенимают некоторые черты старой аристократии, что обеспечивается процедурой голосования, а не выбором в результате жеребьевки, что характерно для античных и ренессансных городов государств. Исследуя, какие исторические изменения претерпевал образ политической репрезентации, современный политический философ Бернар Манен выделяет четыре основополагающих принципа представительного правления:

1. Проводятся регулярные выборы представителей.

2. Существует некоторая независимость решений представителей от желаний представляемых.

3. Представляемые могут выражать свои политические мнения независимо от представителей.

4. Решения проходят публичные испытания дебатами (Манен, 2008: 15). 
Все четыре принципа в разном формате включают в себя предпосылку, что представляемые существуют до представительства — до процедуры выборов, созыва коллективных управляющих органов, публичных дебатов. В случае репрезентации прав и интересов будущих поколений представляемые не существуют ни как обладатели актуальной «общей воли», ни как агенты, способные оспаривать принятые от их имени решения. Т. е. из принципов Манена выполним только второй, но поскольку будущие поколения не способны реагировать на действия представителей, невозможно отличить их «независимость в принятии решений» от их же произвола.

В предыдущем разделе была рассмотрена позиция, согласно которой «говорение от имени» создает, конструирует тех, от чьего имени ведется речь. Действительно, в случае с будущими поколениями мы не можем говорить о том, что они как представляемые способны авторизовать представителей. Кроме того, единственный способ придать правовой или политической репрезентации подотчетность - сконструировать актуальную систему ответственности перед реально существующими агентами. Это не означает, что представительство не имеющих права голоса обречено стать сферой произвола представителей.

Эколог и политический мыслитель Михня Танасеску пытается разработать теорию политической репрезентации природных объектов как реально существующих, но «бессловесных» существ. Он упоминает два способа придать конкретный вектор действиям представителей, ограничить возможность произвольного принятия решений. Первый из этих механизмов основан на конструировании набора минимальных прав, которыми должны обладать все живые существа. Так, Танасеску, упоминает широко обсуждаемый подход $c$ точки зрения возможностей, разработанный Мартой Нуссбаум и Амартией Сеном (Tanasescu, 2016: 22), резюмируя что жизнь является минимальным условием реализации любого набора возможностей. Однако такую тяготеющую к естественному праву конструкцию сложно ориентировать для репрезентации тех, кто еще не появился на свет. Разумеется, технологии, о регулировании которых идет речь, не должны превращать «природное» и «социальное» окружение в среду, непригодную для жизни. Но не менее важными могут оказаться ограничения возможностей будущих поколений, вписанные в возникающие сегодня практики использования и регулирования технологий.

Второй подход, который упоминает М. Танасеску, предполагает интерпретацию прав и интересов тех, кто актуально не может авторизовывать своих представителей или призывать дать отчет за принятые решения. Эта интерпретативная процедура в некоторых моментах напоминает представления Рональда Дворкина о природе права. Но если Дворкин рассматривает судей как соавторов в написании целостного и непрерывного сюжета развития правовых 
принципов и норм, то Танасеску подчеркивает диалогическую природу интерпретации. Он считает, что правильное отношение к животным - то, что в наибольшей степени делает нас людьми (ibid.: 26). Т. е. правильная репрезентация в таком случае тяготеет к пониманию всего живого как целостности, так же как у Дворкина целостная природа права движет судьями.

Данные подходы нельзя считать взаимоисключающими или даже независимыми. Дворкин сумел проинтерпретировать дискуссии об аборте, как споры о понимании ценности жизни (а не собственно о правах эмбриона), апеллируя к определенным традициям в осмыслении руководящих принципов права (Dworkin, 1993). Интерпретации уже предпосланы некоторые ограничения, обусловленные правовым преемством. Образ жизни и ценности будущих поколений могут быть многообразными, но не какими угодно. Накопление знаний о своем геноме и геноме своих предков может быть важным для еще не рожденного индивида, но не менее важным может оказаться для него / нее возможность контролировать то, как некто распоряжается этими геномными данными.

Само же интерпретативное представительство - даже в отсутствии авторизации осуществляющих его субъектов - может быть понято как важная и традиционная часть современной публичной сферы ${ }^{1}$. Известный политический философ Филип Петтит, рассуждая о роли репрезентации в ее функционировании, различает три вида представительства. Индикативное представиmельство предполагает, что коллективный или индивидуальный агент выступает как «аватар», полностью подконтрольный находящимся в другом месте представляемым. Оценки и решения этого субъекта должны быть довольно точным изображением взглядов и интересов тех, кто делегировал ему полномочия (Pettit, 2010: 65). Если представитель обладает большей свободой действия, на него возлагается и большая публичная ответственность. Делегаты как агенты, существующие в рамках директивного представительства в классификации Петтита, - направлены для осуществления определенных функций, но уже без пошаговых инструкций. Так, адвокат может представлять отсутствующего клиента в зале суда (ibid.). Третий тип представительства интерпретативное - связан с необходимостью истолковывать права и инте-

\footnotetext{
${ }^{1}$ Употребляя данное словосочетание, я не пытаюсь использовать связанные с ним теоретические построения, например, Ю. Хабермаса. Для понимания того, в каком смысле слово «публичный» употребляется в текстах Ф. Петтита, достаточно указать на то, что он является одним из создателей современной республиканской теории в политической философии. Публичная сфера таким образом выступает как пространство для постоянного оспаривания принимаемых решений или господствующих взглядов - в том числе и на само существо публичных вопросов.
} 
ресы представляемых. Последние обретают причастность к актуальной публичной сфере благодаря представительству, но это не значит, что они произвольно сконструированы в процессе этого представительства. Так, актер, импровизируя в образе своего героя, не может реагировать на неожиданные раздражители так, как ему угодно. Именно с работой актера Петтит сравнивает этот тип репрезентации (ibid.: 65-66). Актер придает своему герою актуальное существование, но не полностью конструирует его - эпизоду игры и импровизации предшествуют авторские тексты, предыдущие его интерпретации, отзывы критиков и реакция публики. Т. е. эта интерпретация предполагает взаимодействия двух актуально существующих сторон - актера и публики, и одной отсутствующей, но самой важной — героя, как того, кто задает семантику всего происходящего на сцене.

Итак, интересы людей, которые появятся на свет в будущем, могут отличаться от наших. Однако существует возможность их интерпретативного представительства. При этом очевиден риск произвольной интерпретации прав и интересов представляемых. Однако полной релятивизации противостоит сама суть интерпретации, раскрываемая через соавторство уже существующего до нас текста, корпуса права (Дворкин) или через действия актера в уже созданном заранее образе (Петтит). Права и интересы будущих поколений актуализируются исключительно говорящими от их имени, поэтому мы и обратили внимание на делегирование агентности у Латура. Но все же интерпретативные задачи налагают достаточно жесткие ограничения на говорящего. Нельзя составить исчерпывающие инструкции, защищающие права будущих поколений. Но можно сформировать с достаточной уверенностью некоторый образ того, какими возможностями - 'capabilities' в терминах Сена и Нуссбаум - должны обладать еще нарожденные люди. Нуссбаум считает набор этих возможностей достаточно стабильным и формирует их список, ориентируясь на Аристотеля (Nussbaum, 2011).

Список этих возможностей и их отношение к геномным технологиям и распоряжению геномными данными еще предстоит прояснить - вероятно, это тема отдельной статьи ${ }^{2}$. Пока же мы остановимся на двух выводах: во-первых, представительство будущих поколений при обсуждении регулирования этих технологий видится важным и возможным. Во-вторых, интерпретация прав и интересов будущих поколений способна обозначить некоторую значи-

\footnotetext{
2 При этом доступ к качественному здравоохранению можно рассматривать как одну из множества базовых возможностей индивида, в то время как здоровье и социальное благополучие являются составляющими всех возможностей вообще, что, однако, не означает их доминирующего характера (Tengland, 2020).
} 
мую уже сегодня правовую рамку регулирования геномных технологий и геномных исследований. Ниже будут лишь кратко намечены некоторые опорные точки такой рамки.

\section{ЗАКЛЮЧЕНИЕ}

Одной из важнейших проблем соблюдения прав еще не рожденных людей является обеспечение их возможности в будущем контролировать то, каким образом сторонние лица обращаются со значимыми для них генетическими данными. Данное понимание отличается от обеспечения автономии в узком ее смысле. Индивиды не могут рассчитывать на то, что будут «оставлены в покое»: значимые для них геномные данные уже могут быть использованы кем-то до их появления на свет. В этом смысле обеспечить их автономию невозможно. Однако можно дать им возможность контролировать то, что происходит с такими данными (Clayton et al., 2019).

Уже не раз отмечалась важность того, что достигшие возраста дееспособности люди должны иметь право отзывать согласие на использованное их генетическими данными, данное их родителями или законными представителями (Holm, 2005). Однако, возможно, такое же право может иметь место и в отношении геномных данных умерших родителей или иных кровных родственников индивида, поскольку использование этих данных может оказать влияние на его / ее частную жизнь и благополучие.

Соответственно, в форме информированного согласия уместно конкретизировать:

- $\quad$ срок хранения биоматериала и / или генетических данных;

- характер их использования;

- характер их анонимизации;

- варианты отзыва информированного согласия;

- установление права собственности в отношении биоматериала / генетических данных.

Возможно, уместными могли бы быть и законодательные ограничения на сроки хранения и характер использования этих данных, а также варианты отзыва согласия потомками умерших лиц, давших согласие. С большей уверенностью можно предположить, что правом контроля за использованием собственных геномных данных должен обладать любой индивид, вне зависимости от того, давал ли он / она на это информированное согласие. Обсуждение возможностей этих правовых ограничений способно стать важной сферой, в которой осуществляется репрезентация прав и интересов будущих поколений. 


\section{СПИСОК ЛИТЕРАТУРЫ}

Ижевская, В. Л. (2015) Этические проблемы клинического применения генетического тестирования нового поколения // Рабочие тетради по биоэтике. Вып. 21: Философско-антропологические основания персонализированной медицины (междисциплинарный анализ) : сб. науч. ст. / под ред. П. Д. Тищенко. М. : Изд-во Моск. гуманит. ун-та. 208 с. С. 119-136.

Латур, Б. (2013) Наука в действии: следуя за учеными и инженерами внутри общества / пер. с англ. К. Федоровой ; науч. ред. С. Миляева. СПб. : Изд-во Европейского ун-та в Санкт-Петербурге. 414 с. (Прагматический поворот; вып. 6).

Манен, Б. (2008) Принципы представительного правления / пер. с англ. Е. Н. Рощина ; науч. ред. О. В. Хархордин. СПб. : Изд-во Европейского ун-та в Санкт-Петербурге. 323 с. ([RES PUBLICA]; вып. 2).

Напреенко, И. В. (2015) Делегирование агентности в концепции Бруно Латура: как собрать гибридный коллектив киборгов и антропоморфов? // Социология власти. Т. 27. № 1. С. 108-121.

Руссо, Ж.-Ж. (1998) Об общественном договоре, или принципы политического права / пер с фр. А. Д. Хаютина, В. С. Алексеева-Попова // Руссо Ж.Ж. Об общественном договоре. Трактаты. М. : КАНОН-пресс ; Кучково поле. 416 c. C. $195-322$.

Clayton, E. W. et al. (2019) The law of genetic privacy: applications, implications, and limitations / E. W. Clayton, B. J. Evans, J. W. Hazel and M. A. Rothstein. Journal of Law and the Biosciences, vol. 6, no. 1, pp. 1-36. DOI: 10.1093/jlb/1sz007

Dworkin, R. M. (1993) Life's dominion: An argument about abortion, euthanasia, and individual freedom. N. Y. : Knopf. 273 p.

Holm, S. (2005) Informed consent and the bio-banking of material from children // Genomics, Society and Policy. Vol. 1. No. 1. P. 16-26. DOI: $10.1186 / 1746-$ $\underline{5354-1-1-16}$

Jasanoff, S., Hurlbut, J. B. (2018) A global observatory for gene editing // Nature. Issue 555. P. 435-437. DOI: 10.1038/d41586-018-03270-W

Jones, H. (1976) Genetic endowment and obligations to future generations // Social Theory and Practice. Vol. 4. No. 1. P. 29-46.

Knoppers, B. M., Kleiderman, E. (2019) Heritable genome editing: Who speaks for "future" children? // The CRISPR Journal. Vol. 2. No. 5. P. 285-292. DOI: $\underline{10.1089 / \text { crispr.2019.0019 }}$

Nussbaum, M. C. (2011) Creating capabilities: The human development approach. Cambridge, MA ; L. : The Belknap Press of Harvard University Press. xii, [2], $237 \mathrm{p}$. 
Parfit, D. (1982) Future generations: Further problems // Philosophy and Public Affairs. Vol. 11. No. 2. P. 113-172.

Pettit, P. (2010) Varieties of public representation // Political representation / ed. by I. Shapiro, S. C. Stokes, E. J. Wood, A. S. Kirshner. Cambridge ; N. Y. : Cambridge University Press. xi, 368 p. P. 61-89.

Tanasescu, M. (2016) Environment, political representation and the challenge of rights: Speaking for nature. L. : Palgrave Macmillan. ix, 199 p. DOI: $10.1057 /$ $\underline{9781137538956}$

Tengland, P.-A. (2020) Health and capabilities: A conceptual clarification // Medicine, Health Care and Philosophy. No. 23. P. 25-33. DOI: 10.1007/s11019019-09902-w

Дата поступления: 31.03.2020 г.

\section{REFERENCES}

Izhevskaya, V. L. (2015) Eticheskie problemy klinicheskogo primeneniia geneticheskogo testirovaniia novogo pokoleniia [Ethical challenges of clinical application of next generation sequencing]. In: Rabochie tetradi po bioetike [Workbooks on bioethics]. Vol. 21: Filosofsko-antropologicheskie osnovaniia personalizirovannoi meditsiny (mezhdistsiplinarnyi analiz) [Philosophical and anthropological foundations of personalized medicine (Interdisciplinary analysis)] / ed. by P. D. Tishchenko. Moscow : Moscow University for the Humanities Publ. 208 p. Pp. 119-136. (In Russ.).

Latour, B. (2013) Nauka v deistvii: sleduia za uchenymi i inzhenerami vnutri obshchestva [Science in action: How to follow scientists and engineers through society] / transl. from English by K. Fedorova ; ed. by S. Miliaev. St. Petersburg : EUSP Press. 414 p. (Series "Pragmaticheskii povorot" / "The Pragmatic turn"; issue 6). (In Russ.).

Manin, B. (2008) Printsipy predstavitel'nogo pravleniia [The principles of representative government] / transl. from English by E. Roshchin ; ed. by O. V. Kharkhordin. St. Petersburg : EUSP Press. 323 p. ([RES PUBLICA]; issue 2). (In Russ.).

Napreenko, I. V. (2015) Delegirovanie agentnosti v kontseptsii Bruno Latura: kak sobrat' gibridnyi kollektiv kiborgov i antropomorfov? [Delegation of agency in the concept of Bruno Latour: How to build up a heterogeneous collective of cyborgs and anthropomorphs?]. Sotsiologiia vlasti, vol. 27, no. 1, pp. 108-121. (In Russ.).

Rousseau, J.-J. (1998) Ob obshchestvennom dogovore, ili principy politicheskogo prava [The social contract; or, principles of political rights / Du contrat social; ou Principes du droit politique] / transl. from French by A. D. Hayutin and V. S. Alekseev-Popov. In: Rousseau, J.-J. Ob obshchestvennom dogovore. Traktaty 
[The social contract. Treatises]. Moscow : KANON-press ; Kuchkovo pole Publ. 416 p. Pp. 195-322. (In Russ.).

Clayton, E. W. et al. (2019) The law of genetic privacy: applications, implications, and limitations / E. W. Clayton, B. J. Evans, J. W. Hazel and M. A. Rothstein. Journal of Law and the Biosciences, vol. 6, no. 1, pp. 1-36. DOI: 10.1093/jlb/1sz007

Dworkin, R. M. (1993) Life's dominion: An argument about abortion, euthanasia, and individual freedom. New York : Knopf. 273 p.

Holm, S. (2005) Informed consent and the bio-banking of material from children. Genomics, Society and Policy, vol. 1, no. 1, pp. 16-26. DOI: 10.1186/17465354-1-1-16

Jasanoff, S. and Hurlbut, J. B. (2018) A global observatory for gene editing. Nature, issue 555, pp. 435-437. DOI: 10.1038/d41586-018-03270-w

Jones, H. (1976) Genetic endowment and obligations to future generations. Social Theory and Practice, vol. 4, no. 1, pp. 29-46.

Knoppers, B. M. and Kleiderman, E. (2019) Heritable genome editing: Who speaks for "future" children? The CRISPR Journal, vol. 2, no. 5, pp. 285-292. DOI: 10.1089/crispr.2019.0019

Nussbaum, M. C. (2011) Creating capabilities: The human development approach. Cambridge, MA ; London : The Belknap Press of Harvard University Press. xii, [2], $237 \mathrm{p}$.

Parfit, D. (1982) Future generations: Further problems. Philosophy and Public Affairs, vol. 11, no. 2, pp. 113-172.

Pettit, P. (2010) Varieties of public representation. In: Political representation / ed. by I. Shapiro, S. C. Stokes, E. J. Wood and A. S. Kirshner. Cambridge ; New York : Cambridge University Press. xi, 368 p. Pp. 61-89.

Tanasescu, M. (2016) Environment, political representation and the challenge of rights: Speaking for nature. London : Palgrave Macmillan. ix, 199 p. DOI: $\underline{10.1057 / 9781137538956}$

Tengland, P.-A. (2020) Health and capabilities: A conceptual clarification. Medicine, Health Care and Philosophy, no. 23, pp. 25-33. DOI: 10.1007/s11019019-09902-w

Submission date: 31.03.2020.

Шевченко Сергей Юрьевич - кандидат философских наук, научный сотрудник сектора гуманитарных экспертиз и биоэтики Института философии Российской академии наук; доцент кафедры биоэтики лечебного факультета Российского национального исследовательского медицинского университета 
имени Н. И. Пирогова. Адрес: 109240, г. Москва, ул. Гончарная, д. 12, стр. 1. Тел.: +7 (495) 697-90-67. Эл. адрес: $\underline{\operatorname{simurg} 87 @ l i s t . r u}$

Shevchenko Sergei Yurievich, Candidate of Philosophy, Researcher, Department of Humanitarian Expertise and Bioethics, Institute of Philosophy, Russian Academy of Sciences; Associate Professor, Department of Bioethics, Faculty of Medicine, Pirogov Russian National Research Medical University. Postal address: Bldg. 1, 12 Goncharnaya St., 109240 Moscow, Russian Federation. Tel.: +7 (495) 697-90-67. E-mail: simurg87@list.ru

ORCID: 0000-0002-7935-3444

Researcher ID: F-5320-2018

Scopus Author ID: 57192993265

SPIN-код РИНЦ: 2783-6006

Для циитирования:

Шевченко С. Ю. Права будущих поколений и регулирование геномных исследований [Электронный ресурс] // Горизонты гуманитарного знания. 2020. № 2. C. 30-44. URL: http://journals.mosgu.ru/ggz/article/view/1192 (дата обращения: дд.мм.гггг). DOI: 10.17805/ggz.2020.2.2 